\title{
The Psychological Development Effects and Measures for Victims of Bullying in Teenagers
}

\author{
Chu-Iv SUN ${ }^{1, a,{ }^{*}}$ and Jing MU ${ }^{2, b}$ \\ ${ }^{1,2}$ Tianjin University of Science \&Technology ,1038 Dagu South Road, Hexi District, \\ Tianjin, China \\ asuncl625@qq.com \\ ${ }^{*}$ Corresponding author
}

Keywords: Bullying, Governance, Responsibility, Psychological development.

\begin{abstract}
By analyzing the case of bullying in Fujian, mainly show the influences of bullying for teenagers. At the same time, giving the main reasons for this bullying case, and put forward intervention strategies and implement for the bullying cases. Finally, giving the related conclusions.
\end{abstract}

\section{An Overview of Bullying}

There is a piece of news reported in Sohu web in Aug 19th, 2008. A boy born in 1991, who lived in GanDe, a town of FuJian province, killed his classmate, for the person bullying him ten years before at primary school. One day, when the "killer" named WuWen encountered the "enemy" WuGui that always bullied him on the street by accident, he still remember that man bullied him even until a decade later. They quarrel with each other strongly, Wen felt angry and want to revenge, so he called his seven friends came, and give him a hard beating; after Wen and his friends' discussion, they killed Wen's classmate Gui together.

In this paper, the author will mainly explore the psychological consequences for bullied victims in their life and to enhance the focus on teen bullying, and giving the suggestions and solutions on the bullying case.

\section{Influences of Bullying}

Bullying victims can be impacted from biological, psychological, and social aspects. Psychologically, victims are easily suffer from short-term effects such as feelings of low self-esteem, depression, insomnia, anxiety, problems with memory and concentration, desire for revenge, or even suicidal thoughts [1]. At the same time, the effects of bullying could last for a long time, long-term effects can be mental health problems, including schizophrenia, eating-harming behaviors, or post-traumatic stress disorder, etc.

The consequences show that individuals who were bullied in childhood were more likely to have poorer cognitive functioning, psychological and physical health at age fifty [2]. They were also more likely to have lower educational grades, their social relationships, well-being and life satisfaction were also affected. They also have increased risk of anxiety, depression, or even suicidal thoughts.

According to this study, it could be easily found that children who were bullied in school stage were easily have the psychological problem, like the case the author mentioned before, the man killed his classmate because his classmate bullied him before. This case could be ascribed to the psychological problem. But not all of children that been bullied will revenge others, so what are reasons in this case? 


\section{Main Reasons for This Bullying Case}

Firstly, human behavior is easily influenced by the whole circumstance. In China, the first-tier cities, the average cities, the towns and the villages are all developed imbalanced in many aspects, such as economy, urban construction and education etc. As the author mentioned before, Wen's school was located in a small town, so government may not have enough money and hardly given full attention to this small school. They may put the money and their attention on other aspects such as building roads or building bridges. So the whole academic education and quality education levels were at a low developing stage. Teachers may not even notice about Wen's problem, they may mainly focus on students' academic achievement. Teachers may thought that this kind of "trivial thing" are not enough to give the attention to treat. Maybe they never given their enough psychological care to their students, and never mentioned about the importance of the law or make some legal education. These reasons are all the causes of this tragedy happened.

Secondly, Wen may through the low self-esteem during these ten years because Gui bullied him at primary. Gui bullied Wen may have many trivial reasons that the news not mentioned, such as Wen is thin and week than him or Wen's academic scores are not outstanding in class. Wen could not solve his psychological problem through neither himself nor teachers. These factors lead the low self-esteem of him. When he meet Gui on the street by accident even after ten years, and they had strong words with each other, Wen do not want to lose his esteem again, he want to "win" this time, to revenge this man, so the esteem reason lead to the Wen's horrible thought, he want to kill this man and get back his esteem.

Thirdly, Human usually select friends whose characteristics are already similar to theirs, the effect of peers with positive characteristics is as same as the effect of peers with negative characteristics. When Wen call his seven friends to help him kill Gui, none of them told Wen that he have to keep calm and try to stop him about what he want to do. After their discussion, they decide to kill Gui to end this hatred. His friends are not only helping him, but also give him faith and enhance his self-esteem. Because the peers were not give the right instruction in this case, on the contrary, they give the negative suggestions to him, they have the courage to kill this man together. What will we do to prevent this kind of things happen? According to the three reasons, here are intervention strategies that the authors give.

\section{Intervention Strategies and Implement for the Bullying Case}

The core components of the program contains many aspects such as parent involvement, professional development etc. But this program did not include community involvement, such as the law enforcement [3]. Combine with this program and the causes, the author will give the prevention suggestions and implements.

For the first cause the author mentioned before, there are three suggestions as follows, because the community especially the government was not give the full attention on the psychological and legal education, teachers and parents were given inadequate psychological cure to this boy, the young man do not know how to solve this problem in an appropriate way. Except for investing money on the education, they should disseminate more about human psychological development, especially facing bullying. For example, leaders could print some brochures about the importance of the psychological consequences after bullying. The brochures could hand out through teachers should be a guide; they have responsibility to mediate the quarrels. School bullying could be prevented if teachers give a good instruction and give enough 
attention to students.

Victims need emotional care; they need to be supported, understand and accepted [4]. It is important for teachers to give their attention on student's psychological development [5]. If teachers found that the bullying things happen, teacher have to ask clear about the reason for why students bullied this child, talk to this child and let this child talk about the whole things[6]. Teachers could encourage the child from other aspects. For the second cause the author mentioned, the low-esteem of bullied people maybe last for a long time. According to the study about "mental health effects of bullying in childhood are still evident nearly forty years later" the author mentioned before, the psychological issues are the most difficult thing that human have to face. Parents have to encourage their children through many aspects especial from building them self-esteem. For example, parents should ask their children about what happen in school today, the happiest thing and the most sadness thing, to let him talk the sadness thing to prevent the shadow of their heart. Victims also have to protect themselves, if they have some psychological problems at student age, then with the increase of age, they found that the problem at student years give them some negative influences, they have to find out how to deal with it by themselves. For example, if he do not want to tell his families or friends, he may ask help for strangers, such as the experts in psychological, he may go to the professional psychological situation and ask for help about what he has through. So the awareness of seek for help is important, it need to develop and cultivate for a long time by teachers and parents.

\section{Conclusions}

Teachers, parents and policy-makers should notice that bullying is a common part of growing-up; they have to create both a school and home environment characterized by warmth, positive regard, and they need to give attention on early intervention to prevent some potential problems persisting into kid's adulthood, especially on their psychological development. If each person play the correct role on children psychological development, the rate about Wen's case will hard to happen again.

\section{References}

[1] P.H. Berne, L.M. Savary, Building self-esteem in children (expanded edition), Crossroad, New York, 1996.

[2] Information on http://bullying.about.com/od/Bullies/a/6-Consequences-Bullyvictims-Experience.html

[3] P. Ramalingam, Y. Nath, (2012). School psychology in India: A vision for the future. Journal of the Indian Academy of Applied Psychology, 38(1), 22-33.

[4] K. Sally. Bullying-Healtth and medical issues today. American, US: ABC-CLIO, LLC, 64, 2012.

[5] D. R. Shaffer, K. Kipp. Developmental psychology: childhood and adolescence (9th Ed). Belmont, Calif: Wadsworth Cengage Learning (2014).

[6] S. H. Schwartz, A. Bardi. Influences of adaptation to communist rule on value priorities in Eastern Europe. Political Psychology, 18 (1997), 385-410. 